\title{
Market Structure of China's Steel Industry
}

\author{
Juzhen $\mathrm{Wu}$ \\ Department of Mathematics, Jianghan University, Wuhan 430056, China \\ juzhen_wu@163.com
}

Keywords: Market share; Estimation; Market structure; Steel industry

\begin{abstract}
China's steel industry has developed over last 60 years into the world biggest. China accounted for $36.4 \%$ of world steel production and $43.3 \%$ of world total consumption in 2007. It has driven by rapid modernization of its economy, construction, infrastructure and manufacturing industries. This paper employs yearly firm level data from 2005-2007 to test empirically the market share reflected by component variables in the steel industry. We introduced an empirical econometric model of estimation equations and stochastic structure. This permits us to separately identify how efficiency, location, proprietary, and organizational characteristics of a firm affect its market share.
\end{abstract}

\section{Introduction}

China is the world's largest market for steel. The steel industry is gradually increasing and annual crude steel output was 100 million in 1996. It produced 123 million tons of steel in 1999. After its ascension to the WTO it aggressively expanded its production for its growing appetite of manufacturing industries such as automotive vehicles, consumer electronics and building materials. In 2009, China produced over 567 million tons of crude steel, which is 10 times the U.S. production, nearly half of the world's steel.

The Chinese steel industry is dominated by a number of large state-owned groups which are owned via shareholdings by local authorities, provincial governments and even the central authorities. The Chinese steel industry is highly fragmented, with more than 3,000 steel producers, which makes the domestic market highly competitive and difficult to control. Its growth also faces constraints such as dependence on imported iron ore and high energy consumption. The Chinese government has shown interest in stepping up its efforts to rein in steel overcapacity and to consolidate and restructure the steel industry [1]. Many researchers had shown their interests in this research field [2-8].

The objective of this paper is to measure market share structural of Chinese steel industry. We adopted econometric techniques with firm level data form 2005-2007 for a particular industry. This econometric model is design to find the effect of variables on the market share and the changes of market share over time [9-10]. It also aimed to examine whether technology varies among different firm size and ownership of steel industry.

In this paper, the firm level data is from National Audit Department of China of the Chinese steel industry firms and china's import and export data is from world steel association. The annual firm level and national import/export data are used to construct an accurate market share percentage of each firm in this industry. This also permits us to examine the market share for particular group which can by classified by firm size, location and ownership.

\section{Methodology}

This section is concerned with the possibility of estimating a simultaneous equation regression model, in which the parameters can be estimated. In order to study the effects of multiple variables on each firm's market share in the steel industry, we designed an econometric model as below: 
MrkSharei $=\beta 0+\beta 1 * \ln ($ Sales Valuei $)+\beta 2 * \ln ($ Output Valuei $/$ Employeei $)+\beta 3 * \ln ($ Fixed assetsi $/$ Employeei $)+\beta 4 * \ln ($ Material costi $)+\beta 5^{*} \ln ($ Profit totali $)+\beta 6^{*}$ Ownershipi $+\beta 7^{*}$ Locationi $+\beta 8^{*}$ Firm Sizei $+\beta 9 * \ln ($ Research Expi $)+\beta 10 * \ln ($ Advertisementi $)+$ Eit

Where MrkSharei is market share and it is a dependent variable. Ownershipi, Locationi, and Firm Sizei are dummy variables. Table 1 , lists all variables and their explanations in this model.

Table 1 List of Variables

\begin{tabular}{ll}
\hline Output Value & Total output \\
Fixed Assets & \\
Output Value/Employee & Product efficiency \\
Fixed Assets/ Employee & \\
Employee & Yearly average \\
Profit total & \\
Material Cost & \\
Advertisement & \\
Research Exp & \\
Constant & \\
Firm Size & \\
Location & Big, medium, small \\
Ownership & Costal, inland \\
\hline
\end{tabular}

Firstly, we used pooled ordinary least squares (POLS) method to estimate those estimators. POLS corresponds to running OLS on the observations pooled across $i$ and t. We mentioned this estimator in the context of independent cross sections. In the panel data case,

$$
\sum_{i=1}^{N} \mathbf{X}_{i}^{\prime} \mathbf{X}_{i}=\sum_{i=1}^{N} \sum_{t=1}^{T} \mathbf{x}_{i t}^{\prime} \mathbf{x}_{i t} ; \quad \sum_{i=1}^{N} \mathbf{X}_{i}^{\prime} \mathbf{y}_{i}=\sum_{i=1}^{N} \sum_{t=1}^{T} \mathbf{x}_{i t}^{\prime} y_{i t}
$$

Therefore, we can write $\hat{\boldsymbol{\beta}}$ as

$$
\hat{\boldsymbol{\beta}}=\left(\sum_{i=1}^{N} \sum_{t=1}^{T} \mathbf{x}_{i t}^{\prime} \mathbf{x}_{i t}\right)^{-1}\left(\sum_{i=1}^{N} \sum_{t=1}^{T} \mathbf{x}_{i t}^{\prime} y_{i t}\right)
$$

The estimator in equation (1) is for the same cross section units sampled at different points in time. The appropriate estimator of $(\beta)$ is:

$$
\hat{\sigma}^{2}\left(\mathbf{X}^{\prime} \mathbf{X}\right)^{-1}=\hat{\sigma}^{2}\left(\sum_{i=1}^{N} \sum_{t=1}^{T} \mathbf{x}_{i t}^{\prime} \mathbf{x}_{i t}\right)^{-1}
$$

where $\sigma 2$ is the usual OLS variance estimator from the pooled regression.

Secondly, we used maximum-likelihood estimation (MLE) method to optimize the market share for individual firms and to provide estimates for the model's parameters. This would help firms in china's steel industry to increase their market share and profit as well. In this study, it is often more convenient to work with the logarithm of the likelihood function, called the log-likelihood: 


$$
\ln \mathcal{L}\left(\theta \mid x_{1}, \ldots, x_{n}\right)=\sum_{i=1}^{n} \ln f\left(x_{i} \mid \theta\right),
$$

Where $\mathrm{f}(\mathrm{xi})$ is the probability density of endogenous variables and dummy variables.

\section{Data}

In this study, we use firm-level data of China's steel industry at the year of 2007. Each observation in our dataset includes the information on a number of variables for different individual industrial units covered by National Audit Department of China (NADC). Here, we chose Industrial output value (prices at 2007), fixed asset, employee number, advertisements expense, research and develop expense, material cost and the yearly total profit as endogenous variables. The dummy variables are location, firm size and ownership. Table 2, indicates the data variables, period, size and sources.

Table 2 Inventory of Data Sets

\begin{tabular}{llll}
\hline Variables & Period & Size & Source \\
\hline Total Export & $2000-2010$ & Yearly Aggregate Data & WSA \\
Total Import & $2000-2010$ & Yearly Aggregate Data & WSA \\
Annual total revenue & $2004-2007$ & 4347 Firm-level Data & NADC \\
Total assets & $2004-2007$ & 4347 Firm-level Data & NADC \\
Industrial output & $2004-2007$ & 4347 Firm-level Data & NADC \\
Total sales value & $2004-2007$ & 4347 Firm-level Data & NADC \\
Employees & $2004-2007$ & 4347 Firm-level Data & NADC \\
Fixed assets & $2004-2007$ & 4347 Firm-level Data & NADC \\
Ownership & $2004-2007$ & 4347 Firm-level Data & NADC \\
Profit total & $2004-2007$ & 4347 Firm-level Data & NADC \\
Material cost & $2004-2007$ & 4347 Firm-level Data & NADC \\
Other cost & $2004-2007$ & 4347 Firm-level Data & NADC \\
Location & $2004-2007$ & 4347 Firm-level Data & NADC \\
Firm Size & $2004-2007$ & 4347 Firm-level Data & NADC \\
R\&D expenses & $2004-2007$ & 4347 Firm-level Data & NADC \\
Advertisement & $2004-2007$ & 4347 Firm-level Data & NADC \\
*WSA: World Steel Association & & & \\
* NADC: National Audit Department of China & &
\end{tabular}

\section{Results}

The main findings of our empirical analysis can be summarized that the ratios of Output Value to Employee, ratio of Fixed Assets to Employee and Advertisement have positive effect on market share. Firms with big size and in coastal area are both indicate higher market share in the steel industry. The reason is that big firms have more productivity than small firms and coastal area has high percentage of total consumers in the market of china. Moreover, numbers of employee, medium and small size firms have the negative effect on market share. Another important thing need to be mention is four ownership type are all have negative effect. 
Table 3 Estimated Results

\begin{tabular}{lll}
\hline & OLS & MLE \\
\hline $\ln$ (Output Value) & $3.43 \mathrm{E}-07$ & $-5.79 \mathrm{E}-06$ \\
$\ln$ (Fixed Assets) & $2.23 \mathrm{E}-07$ & $2.88 \mathrm{E}-06$ \\
$\ln$ (Output Value/Employee) & 0.000594 & -0.00207 \\
$\ln$ (Fixed Assets/Employee) & 0.003077 & -0.00548 \\
$\ln$ (Employee) & $-1.64 \mathrm{E}-05$ & $3.87 \mathrm{E}-05$ \\
$\ln$ (Profit total) & $-6.29 \mathrm{E}-07$ & $-2.72 \mathrm{E}-06$ \\
$\ln$ (Material Cost) & $-5.91 \mathrm{E}-07$ & $4.68 \mathrm{E}-06$ \\
$\ln$ (Advertisement) & 0.000303 & -0.00861 \\
$\ln$ (Research Exp) & $8.90 \mathrm{E}-06$ & -0.00018 \\
Constant & -4.24516 & -3.31505 \\
Firm Size(big) & 0.273216 & 43.15639 \\
Firm Size(medium) & -2.74488 & 2.389719 \\
Firm Size(small) & -0.80713 & 3.587556 \\
Location & 0.044034 & 1.682442 \\
Ownership(national) & -0.65366 & 13.58331 \\
Ownership(group) & -0.70051 & -4.48715 \\
Ownership(private) & -0.60074 & -2.87972 \\
Ownership(foreign) & -0.19245 & 2.638964 \\
\hline
\end{tabular}

\section{Conclusion}

In this study, we measure the levels of firm's market share in China's steel industry from 2004 - 2007. Our study is aimed to find the impact on firm's market share by the endogenous variables. This is helpful to better understand the market structure in China's steel industry and to increase the competitive of china's firms in both domestic and international market. Further works can be focus on the separate groups by firm size and ownership to study the efficiency and market share changes over time.

\section{References}

[1] Rachel Tang, "China's Steel Industry and Its Impact on the United States: Issues for Congress", Congressional Research Service. (2010)

[2] Bhandari, A. K. and P. Maiti, "Efficiency of Indian Manufacturing Firms: Textile Industry as a Case Study", International Journal of Business and Economics, 6 (1), 71-88. (2007)

[3] Charnes, A., W. W. Cooper, and E. Rhodes, "Measuring the Efficiency of Decision Making Units", European Journal of Operational Research, 2 (6), 429-444. (1978)

[4] Haiyan Deng, Alyson C. Ma, "Market structure and pricing strategy of China's automobile industry", The Journal of Industrial Economics, Vol. LVIII. (2010) 
[5] Kadiyali, K., Sudhir, K., Rao, V., "Structural analysis of competitive behavior: New Empirical Industrial Organization methods in marketing Intern", Journal of Research in Marketing, 18 (2001). 161-186. (2001)

[6] Ray, S. C., "Did India's Economic Reforms Improve Efficiency and Productivity? A Nonparametric Analysis of the Initial Evidence from Manufacturing", Indian Economic Review, 37 (1), 23-57. (2002)

[7] Bhandari, Anup Kumar and Ray, Subhash C., "Technical Efficiency in the Indian Textiles Industry: A Nonparametric Analysis of Firm-Level Data". Economics Working Papers. Paper 200749. (2007)

[8] He, Weida, Xuejun Wan and Yabin Wu, "Study on Competitiveness of China's Iron and Steel Industry Based on the Strategic Capability-based View", China Industrial Economics, 260(11), 5665. (2009)

[9] Ray, S. C., "Data Envelopment Analysis: Theory and Techniques for Economics and Operations Research", Cambridge University Press. (2004)

[10]Wooldridge, J., "Econometric Analysis of Cross Section and Panel Data", MIT Press. (2002) 